\title{
Design and Analysis of The Energy Storage and Return (ESAR) Foot Prosthesis Using Finite Element Method
}

\author{
Alfiana Fitri Istiqomah ${ }^{1,2}$, Rifky Ismail ${ }^{1,2^{*}}$, Deni Fajar Fitriyana ${ }^{1,3}$, Sulistyo $^{2}$, Akmal Putra \\ Fardinansyah $^{1,3}$, Murti Ayu Nur Safitri ${ }^{1,3}$, Januar Parlaungan Siregar ${ }^{4}$ \\ ${ }^{1}$ Center for Biomechanics, Biomaterial, Biomechatronics, and Biosignal Processing, Diponegoro University \\ Semarang, Indonesia \\ ${ }^{2}$ Mechanical Engineering dept. Diponegoro University Semarang, Indonesia \\ ${ }^{3}$ Mechanical Engineering dept.Universitas Negeri Semarang Semarang, Indonesia \\ ${ }^{4}$ College of Engineering, Universiti Malaysia Pahang, 26300 Gambang, Pahang, Malaysia
}

\begin{abstract}
Disability issue has increased in recent years due to the high number of accidents and vascular disease. Loss of limb function for people with amputations often results in an abnormal gait. Energy Storage And Return (ESAR) foot prostheses provide an alternative to help improve gait and minimize metabolic energy expenditure during the walking phase of amputees. This study used 3 designs with models from the Catia V5 Software. The finite element method analysis used Ansys Workbench 18.1 software to evaluate the three designs with a loading of 1.2 times the user's body weight with a maximum weight of $70 \mathrm{~kg}$ in normal walking activities. The simulated material is carbon fiber prepreg which has tensile strength, Young's modulus, Poisson ratio, and density of $513.72 \mathrm{MPa}, 77.71 \mathrm{GPa}, 0.14$, and $1.37 \mathrm{~g} / \mathrm{cm} 3$. The decision-making matrix method is used to determine the best foot prosthesis design according to predetermined criteria. The highest value in the decision-making matrix is 76 in Design 3. The chosen design (Design 3) after gait cycle analysis has a maximum von Mises stress value of $76.956 \mathrm{MPa}$ and the safety factor value for each gait cycle heel strike loading model is 1.0762; foot flat 3.2509; toe-off 6.6263.
\end{abstract}

Keywords: The Energy Storage and Return (ESAR) Foot, Foot Prosthesis, Finite Element Analysis, Carbon-Fibre Prosthesis, Ansys

Article History: Received xxx; Received in revised form xxxx; Accepted xxx; Available online: xxx (7.5 pt)

DOI: $10.14710 /$ jbiomes.X.X.Xxx-Xxx

\section{INTRODUCTION}

In recent years, disability has become an issue in Indonesia due to the high number of traffic accidents and vascular diseases. The number of accidents in Indonesia is increasing every year. Data from the Central Statistics Agency in 2017 recorded that 104,327 people had accidents, in 2018 there were 109,215 people, and in 2019 it increased to 116,411 people [1]. In 2010 there were about 3.1 million people experiencing amputations, the percentage increased from $35.5 \%$ to $54.8 \%$ so they had difficulty moving their lower limbs [2].

The loss of limb function for people with amputations often results in an abnormal gait. Foot prosthesis is very important for amputees to carry out daily activities such as walking, running, jogging, cycling, and other activities [3]. Currently, active prostheses with internal force sources are still in the development stage [4-6] passive prostheses are currently still dominating the market. The prosthesis is expected to be able to maximally replicate the function of the missing limb.

Generally, amputees use a prosthesis foot with a Solid Ankle Cushioned Heels (SACH Foot) design which function is reducing impact only and storing and releasing very little elastic energy [7]. In addition, $\mathrm{SACH}$ is the most common and basic non-articulated prosthetics of the foot [8] in that it has no moving parts [9]. This causes a high expenditure of metabolic energy from an amputee.

Energy Storage And Return (ESAR) foot prostheses provide an alternative to help improve gait [10]. In addition, the ESAR foot prosthesis has long been assumed to minimize metabolic energy expenditure during the walking phase in amputees [11].

Lee [12] has developed a multi-axis prosthetic ankle joint to mimic the ankle joint of a real human foot. However, Lee's prosthesis was able to store only a small amount of elastic energy.

Carbon fiber composite material with an epoxy resin matrix is an ideal material for orthopedic applications such as foot prostheses, due to its lightweight and durable properties [13]. Although prostheses made from carbon fiber are light in weight, this is an advantage because when used they can minimize the body's metabolic energy expenditure for an amputee [14]. The main characteristic of composite prosthetics is that they can be custom-made according to each individual's height, weight, and muscle structure [13].

This study proposes Energy Storage and Returns (ESAR) prosthetic foot with a fabrication process using EMRCC (Extended Manufacture Recommended Curing Cycle) with carbon fiber prepreg material. The ESAR Foot Prosthetic

\footnotetext{
*Corresponding author: rifky_ismail@ft.undip.ac.id
} 
design is optimized through 3 proposed designs. The three proposed designs are inspired by Ossur's commercial products. Design 1 is inspired by the Vari Flex series, Design 2 is inspired by the Flex-Foot Assure series, and Design 3 is inspired by the LP-Vari Flex series. Then do the making of geometric designs from Designs 1-3. Finite element analysis was performed to evaluate the biomechanical behavior of the three designs. A decision-making matrix is made to make the best design conclusions are selected. Dynamic simulations adapted to the walking cycle (heel strike, foot flat, toe-off) were carried out to see the mechanical behavior of the selected design.

\section{Materials ANd Methods}

The material used in this research is carbon fiber prepreg with an epoxy resin matrix. Fiber direction orientation 0o/90o. The fabrication method used is the EMRCC (Extended Manufacturer Recommended Curing Cycle) method. In this prosthesis leg, the design must meet the criteria of being able to withstand a weight of $70 \mathrm{~kg}$ with a loading of 1.2 times the weight for normal walking activities [15] So this prosthesis leg must be able to withstand a maximum weight of $84 \mathrm{Kg}$, so that the static loading on the Ansys Software uses a force of 823.7 N.

The design of the prosthesis leg geometry using Catia V5 Software and simulated with Ansys Workbench 18.1 Software to determine the maximum Von-Mises stress, deformation, total stretch elasticity, and safety factor of the prosthesis of the foot.

The biomedical approach is discussed to see possible applications when used by amputees. To determine the best design from several alternative designs that have been made, an assessment is carried out based on the decision-making matrix. Gait cycle simulation on the design was carried out to see the mechanical behavior of the foot prosthesis design product.

\section{RESUlt AND DISCUSSION}

The foot prosthesis can ideally help the patient to achieve a natural gait pattern, including dorsiflexion, eversion, shock absorber, energy absorption and energy return, and ankle torsion [13]. The designed product must also meet the affordable cost with the right composite fabrication method.

A. Design Criteria

The criteria to be achieved:

a. Able to withstand a load 1.2 times the average human body weight [15]

b. Able to dampen vibration when heel contact (heel strike and shock absorber)

c. Able to reach a flat position (foot-flat) vastly

d. Able to store energy and release it during the toeoff phase

e. Durable

f. Affordable

g. Easy to be used and repaired

B. Selection of Geometrical Design
The design of the prosthesis leg geometry is using Catia V5 Software and simulated with Ansys Workbench 18.1 Software. Figure 1-3 shows the geometric design proposed in this study.
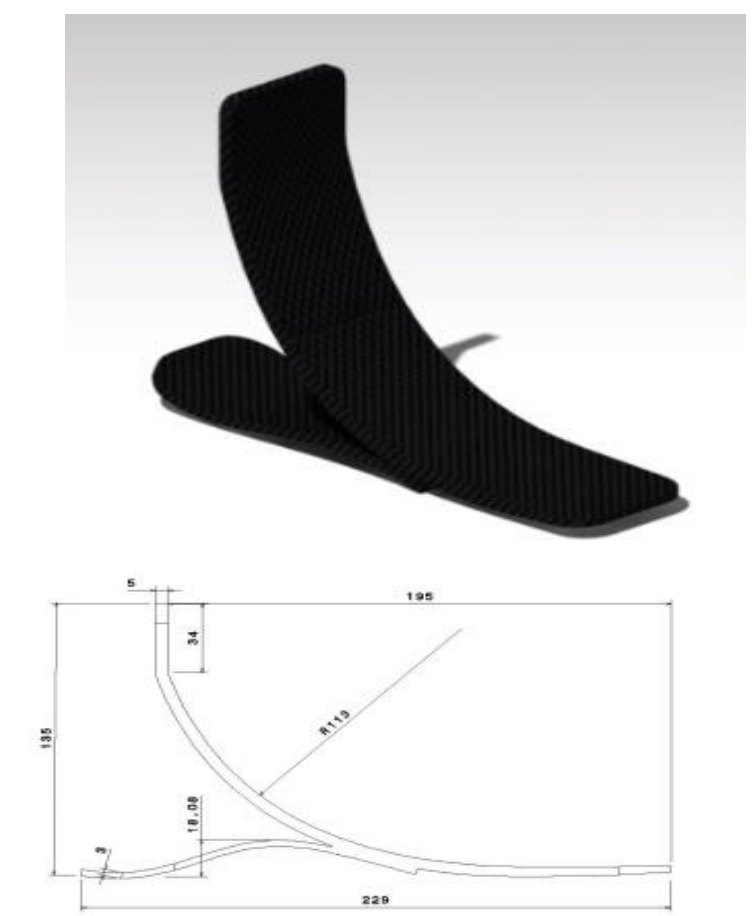

Froest vitest

Figure 1. Geometric Design 1
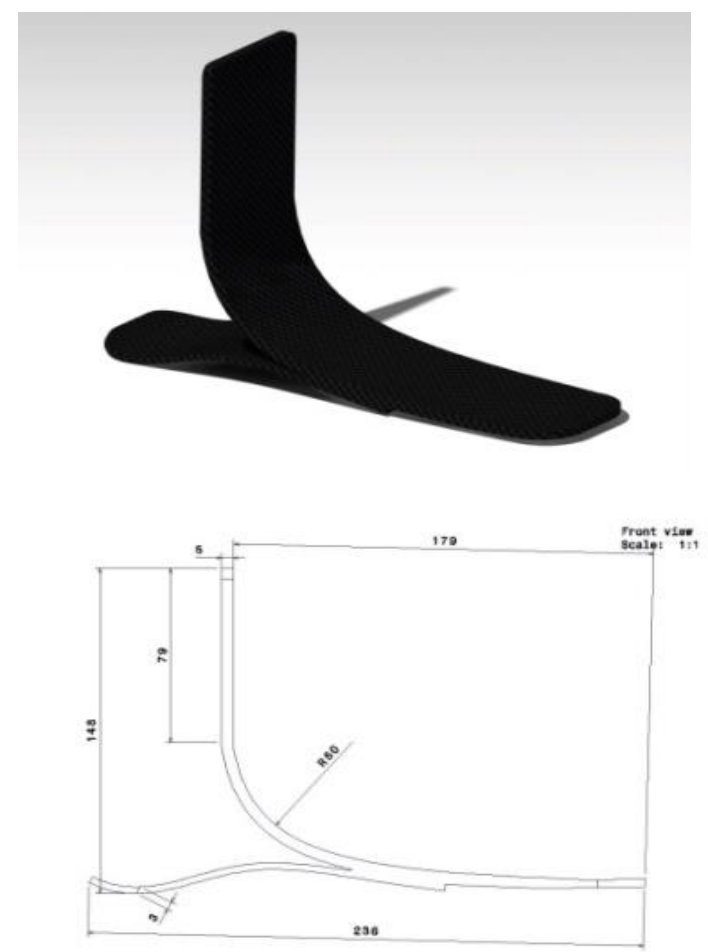

Figure 2. Geometric Design 2 


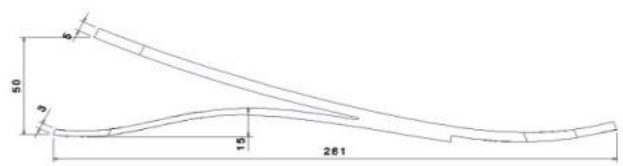

Front vies:

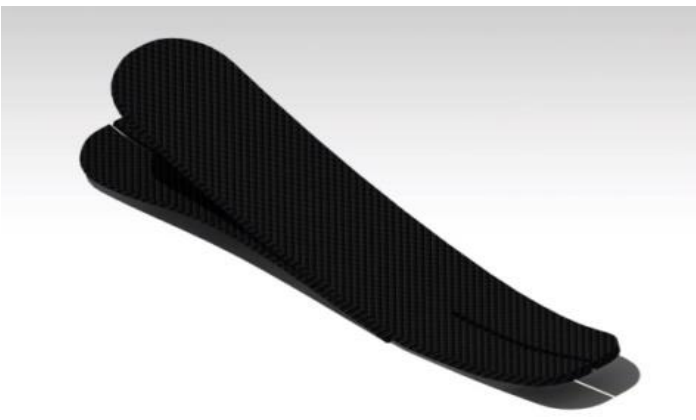

Figure 3. Geometric Design 3

Of the three designs, static testing was carried out using Ansys Workbench 18.1 software with the mechanical properties of carbon fiber prepreg with fiber orientation $0^{\circ} / 90^{\circ}$ with the EMRCC (Exended Manufacturer Recommended Curing Cycle) fabrication method. as in Table 1. In this prosthesis leg, the design must meet the criteria of being able to withstand a weight of $70 \mathrm{~kg}$ with a loading of 1.2 times the weight for normal walking activities [15].

By that, this prosthesis leg must be able to withstand a maximum weight of $84 \mathrm{Kg}$, so that the static loading on the Ansys Workbench 18.1 software uses a force of $823.7 \mathrm{~N}$.

\section{Simulation Result}

The simulation in this study was carried out using Ansys Workbench 18.1 software to determine the maximum VonMises stress, deformation, total elastic strain, and safety factor of the three-foot prosthesis designs. Figure 4-6 shows the results of the static simulation on the foot prosthesis design.

Table 1. Material properties of carbon fiber prepreg composite [16]

\begin{tabular}{lll} 
No. & Mechanical Characteristic & Value \\
\hline 1. & Density & $1.37 \mathrm{~g} / \mathrm{cm}^{3}$ \\
\hline 2. & Tensile strength & $513.72 \mathrm{MPa}$ \\
\hline 3. & Young's modulus & $77.71 \mathrm{GPa}$ \\
\hline 4. & Poisson ratio & 0.14 \\
\hline
\end{tabular}

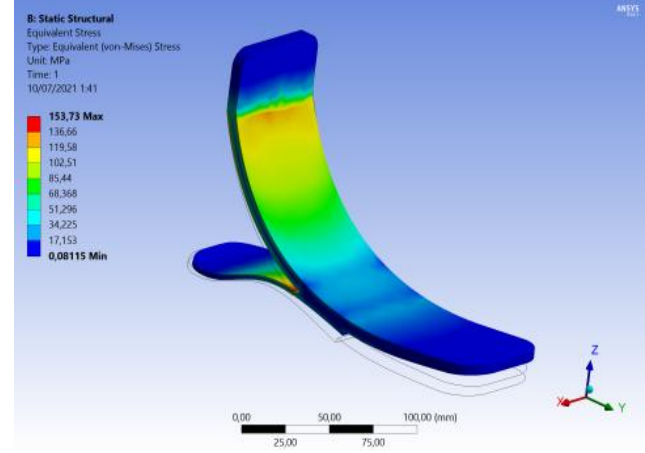

Figure 4. Maximum Von-Mises Voltage of Design 1

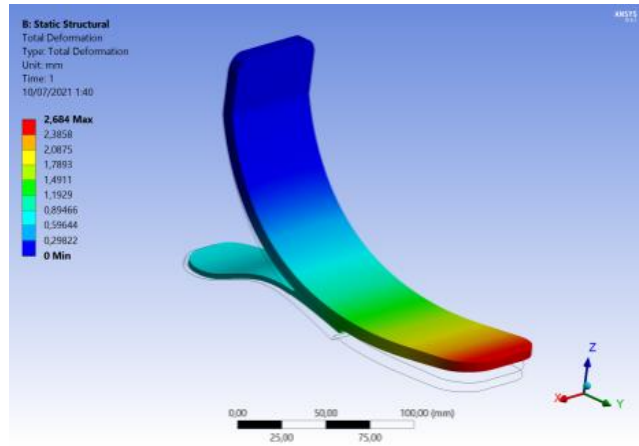

Figure 5. Deformation of Design 1

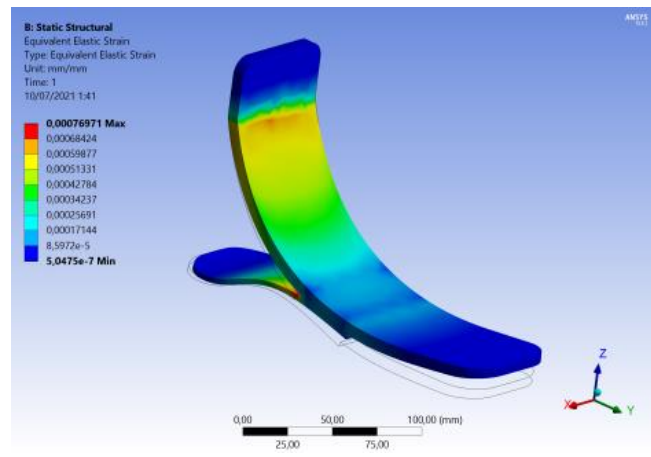

Figure 6. Total Stretch Elasticity of Design 1

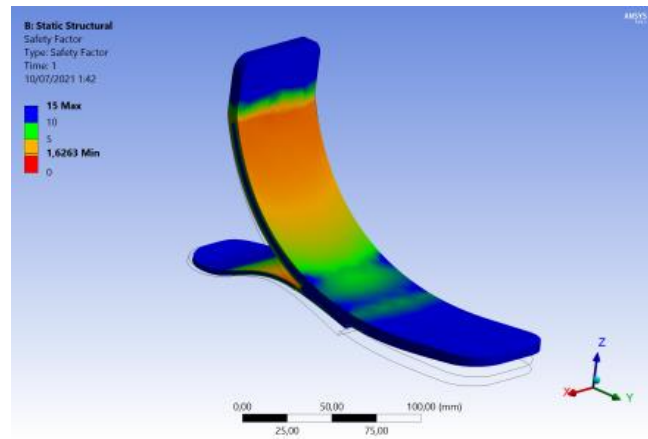

Figure 7. Safety Factor of Design 1 


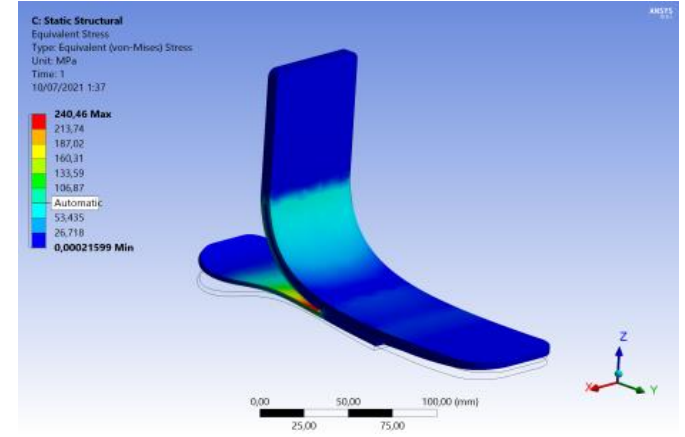

Figure 8. Maximum Von-Mises Voltage of Design 2

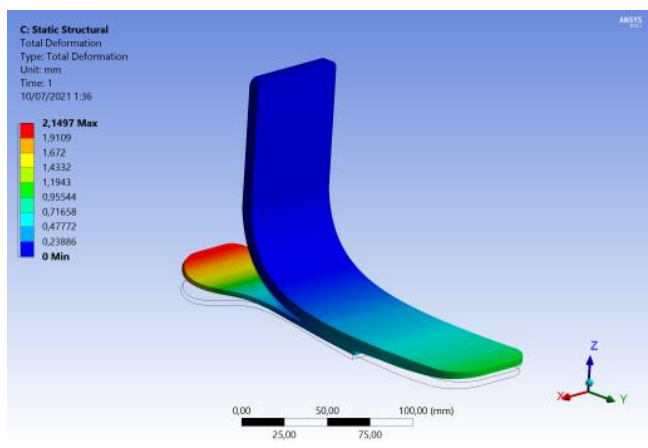

Figure 9. Deformation of Design 2

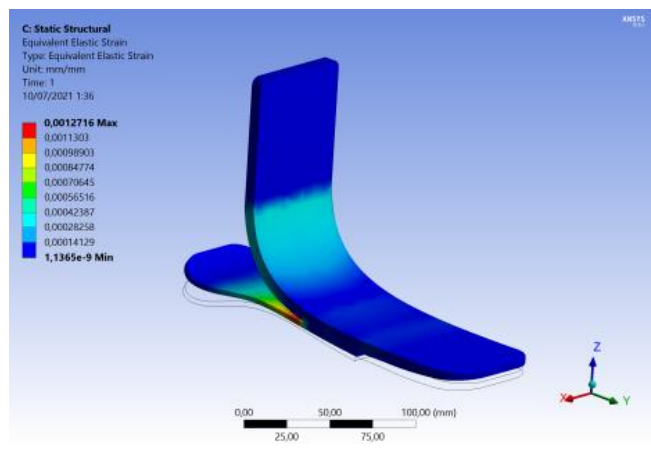

Figure 10. Total Stretch Elasticity of Design 2

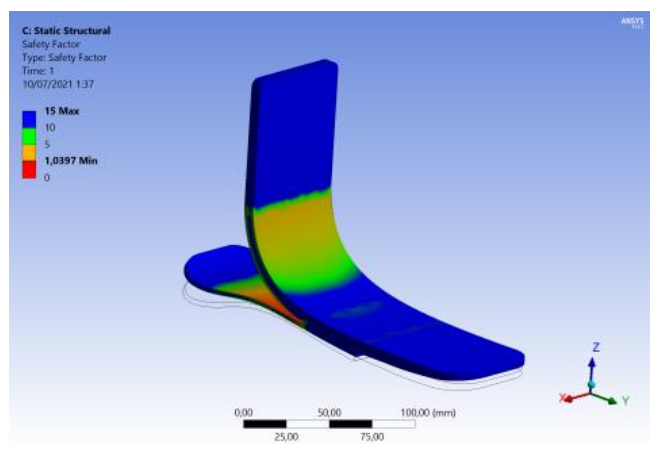

Figure 11. Safety Factor of Design 2

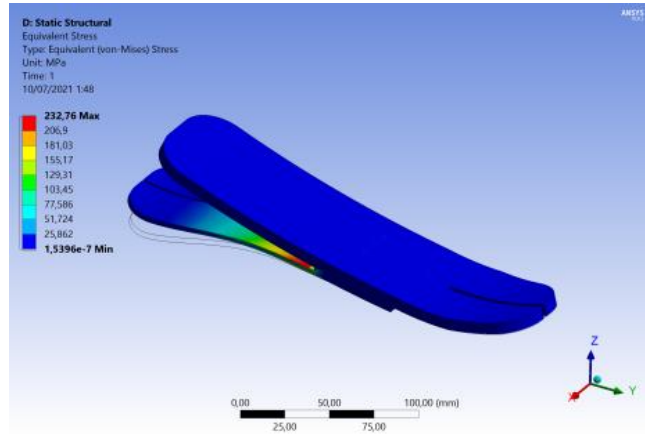

Figure 12. Total Stretch Elasticity Design 2

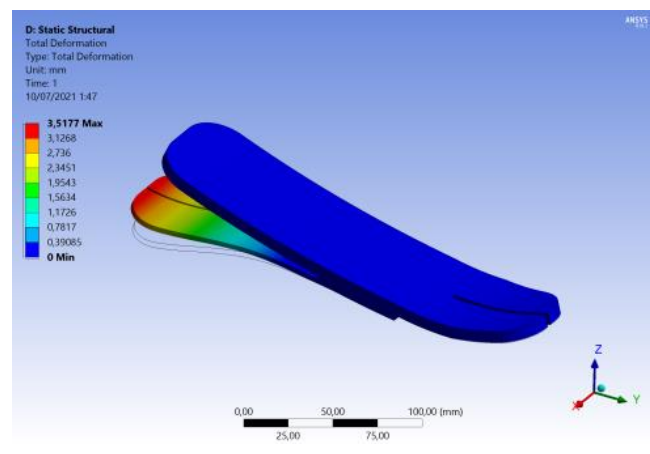

Figure 13. Deformation Design 3

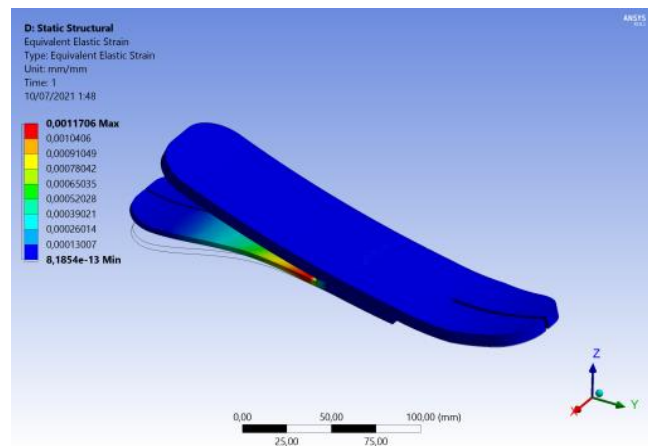

Figure 14. Total Stretch Elasticity of Design 3

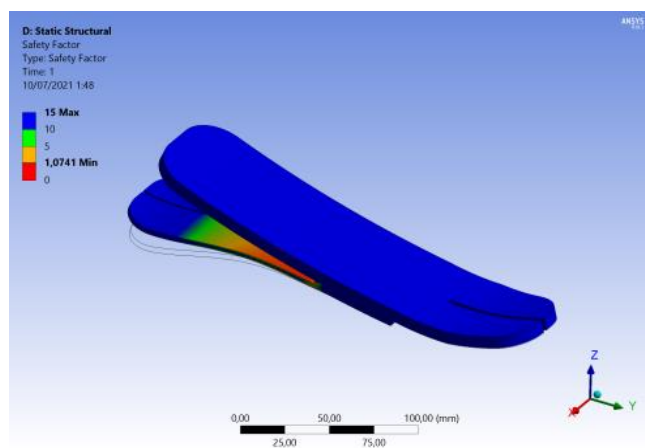

Figure 15. Safety Factor of Design 3 
TABLE 2. DESIGN DECISION MAKING OF MATRIX 1

\begin{tabular}{ccccc} 
No. & Assessment Criteria & Weight & Score & $\begin{array}{c}\text { Weight } \\
\text { Score }\end{array}$ \\
\hline 1 & Material needed & 3 & 5 & 15 \\
\hline 2 & Ease of production & 2 & 4 & 8 \\
\hline 3 & Mass & 3 & 4 & 12 \\
\hline 4 & Application possibility & 4 & 4 & 16 \\
\hline 5 & Safety factor & 5 & 4 & 20 \\
\hline & Total & & & $\mathbf{7 1}$
\end{tabular}

\section{TABLE 3. DESIGN DECISION MAKING OF MATRIX 2}

\begin{tabular}{ccccc} 
No. & Assessment Criteria & Weight & Score & $\begin{array}{c}\text { Weight } \\
\text { Score }\end{array}$ \\
\hline 1 & Material needed & 3 & 4 & 12 \\
\hline 2 & Ease of production & 2 & 3 & 6 \\
\hline 3 & Mass & 3 & 4 & 12 \\
\hline 4 & Application possibility & 4 & 3 & 12 \\
\hline 5 & Safety factor & 5 & 3 & 15 \\
\hline & Total & & & $\mathbf{5 7}$
\end{tabular}

\section{TABLE 4. DESIGN DECiSion MAKING OF MATRIX 3}

\begin{tabular}{ccccc} 
No. & Assessment Criteria & Weight & Score & $\begin{array}{c}\text { Weight } \\
\text { Score }\end{array}$ \\
\hline 1 & Material needed & 3 & 3 & 9 \\
\hline 2 & Ease of production & 2 & 5 & 10 \\
\hline 3 & Mass & 3 & 4 & 12 \\
\hline 4 & Application possibility & 4 & 5 & 20 \\
\hline 5 & Safety factor & 5 & 5 & 25 \\
\hline & Total & & & $\mathbf{7 6}$
\end{tabular}

From the decision-making matrix, the design with the highest score is the chosen design. From Table 2-4, it can be seen that design 3 gets the highest score with a total score of 76.

\section{Analysis Of Gait CyCle}

Gait is a cyclic phenomenon that can be divided into segments or phases. The walking cycle is divided into two, namely the standing phase and the swing phase [17]. In the swing phase, the foot is not on the ground ( $40 \%$ of a walking cycle), whereas in the stance phase, the foot is on the ground (60\% of a walking cycle) [17]. The swing phase consists of the initial swing, mid swing, and terminal swing. The stance phase consists of initial contact (heel strike), mid stance (foot flat), and terminal stance (push off-toe off) [18].

The simulation in this study, using the Ansys Worldbench 18.1 software, carried out 3 variations of loading, namely in the heel strike, foot flat, and toe-off phases so that it seemed as if the foot was experiencing a gait cycle. In the heel strike phase of the foot touching the ground, the foot prosthesis must be able to function as a vibration damper. Then when the patient stands fully in the foot flat phase, the elastic energy is deflected and stored. Dorsiflexion movement in the stance phase releases some of the energy in the heel and transfers some of it to other parts of the foot prosthesis. The foot prosthesis accumulates mechanical energy through the elastic structure in the heel strike to foot flat phase and releases this energy to assist the patient to propel the body forward in the toe-off phase [13].

In designing the design of a product, it is certain that the safety factor of the product made is influenced by the material used. During the simulation process, the three loading phases in Figure 17 are applied which resemble the three phases in the gait cycle: heel strike, foot flat and toeoff.

Based on these data, the prepreg carbon fiber composite material allows it to withstand a maximum load of 76.956 $\mathrm{MPa}$ in a prosthetic leg design simulation with a safety factor $>$ 1, namely Heel strike 1.0762; Foot flat 3.2509; Toe-off 6.6263 .

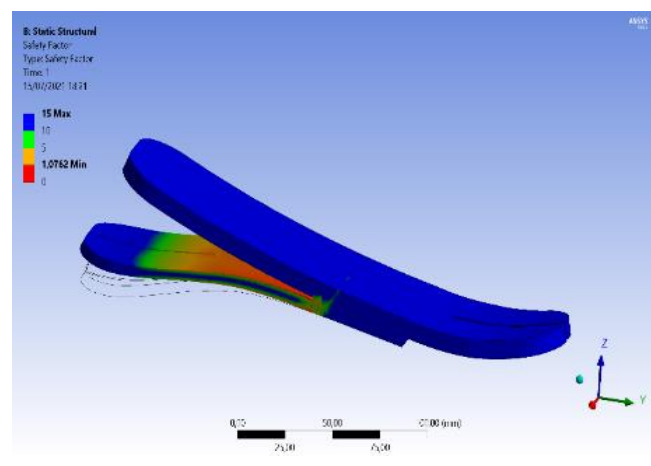

(a)

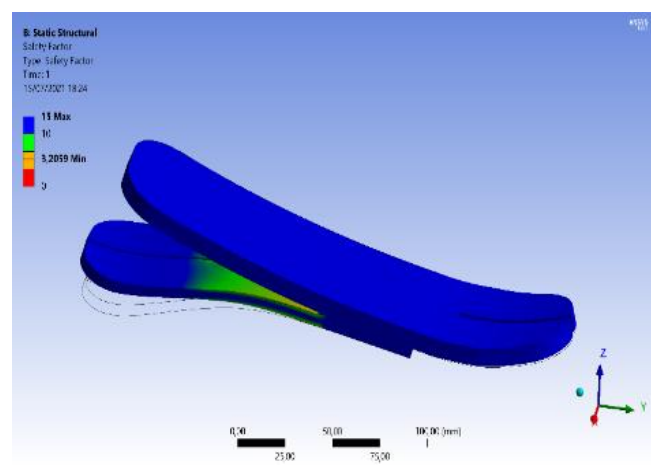

(b)

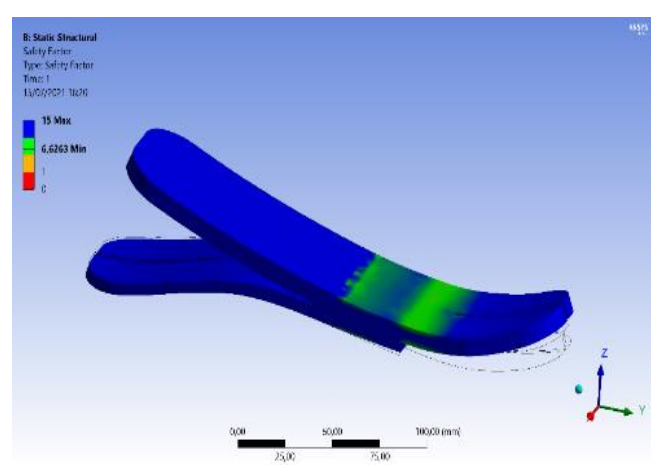

(c)

Figure 17. Three loading phases during the running cycle: (a) Heel strike, (b) Foot flat (c) Toe-off 


\section{CONCLUSION}

Based on the results of the decision-making matrix and modeling with finite element analysis (FEA) simulations, it can be concluded that the design with the highest score is seen from several assessment criteria, namely Design 3 with a score of 76. The selected design then entered the gait cycle analysis stage (heel strike, foot flats and toe-offs).

The selected design (Design 3) after gait cycle analysis has a maximum von Mises stress value of $76.956 \mathrm{MPa}$ and a safety factor value for each gait cycle heel strike loading model 1.0762; foot flat 3.2509; toe-off 6.6263.

Design 3 which has been designed and simulated through computer simulations is proven to be able to withstand a load of 1.2 times the user's body weight with a weight of $70 \mathrm{~kg}$ with a safety factor value of $>1$.

\section{REFERENCES}

[1] Data Kecelakaan di Indonesia Tahun 2017-2019. Badan Pusat Statistik. 2020.

[2] Ramani, G. V., Go, A., \& Olney, D. K. (2020). Gender, poverty and disability in the National Action Plan for Food and Nutrition 2017-2019 of Indonesia and ways forward. Intl Food Policy Res Inst..

[3] Debta, S., \& Kumar, K. (2018). Static Structural Analysis of a Powered Ankle Foot Prosthesis Mechanism. Materials Today: Proceedings, 5(5), 11616-11621..

[4] Kim, H., Shin, Y. J., \& Kim, J. (2017). Design and locomotion control of a hydraulic lower extremity exoskeleton for mobility augmentation. Mechatronics, 46, $32-45$.

[5] Long, Y., Du, Z., Chen, C., Wang, W., He, L., Mao, X., \& Dong, W. (2017). Development and analysis of an electrically actuated lower extremity assistive exoskeleton. Journal of Bionic Engineering, 14(2), 272-283..

[6] Torrealba, R. R., Udelman, S. B., \& Fonseca-Rojas, E. D. (2017). Design of variable impedance actuator for knee joint of a portable human gait rehabilitation exoskeleton. Mechanism and Machine Theory, 116, 248-261.

[7] South, B. J., Fey, N. P., Bosker, G., \& Neptune, R. R. (2010). Manufacture of Energy Storage and Return Prosthetic Feet Using Selective Laser Sintering. Journal of Biomechanical Engineering, 132, 015001-1..

[8] Arifin, N., Osman, N. A. A., Ali, S., \& Abas, W. A. B. W. (2014). The effects of prosthetic foot type and visual alteration on postural steadiness in below-knee amputees. Biomedical engineering online, 13(1), 1-10..
[9] Silver-Thorn, M. B. (2002). Design of artificial limbs for lower extremity amputees. Standard handbook of biomedical engineering and design. New York, USA: McGraw-Hill Professional, 33-1.

[10] Hafner, B. J., Sanders, J. E., Czerniecki, J., \& Fergason, J. (2002). Energy storage and return prostheses: does patient perception correlate with biomechanical analysis?. Clinical Biomechanics, 17(5), 325-344.

[11] Gardiner, J. D., Bari, A. Z., Howard, D., \& Kenney, L. P. J. (2016). Transtibial amputee gait efficiency: Energy storage and return versus solid ankle cushioned heel prosthetic feet. Journal of rehabilitation research and development, 53(6), 1133-1138.

[12] Lee, C.L., Colvin, J.M. and Arbogast, R.E., Ohio Willow Wood Co, 2004. Multi-axis prosthetic ankle joint. U.S. Patent 6,699,295.

[13] Pham, Huy-Tuan, Phan, Thanh-Vu and Mai, VanTrinh. 2020, Optimization Design of a Carbon Fibre Prosthetic Foot for Amputee. Acta Scientific Orthopaedics, pp. 16-21.

[14] Nolan, L. 2008, Carbon fibre prostheses and running in amputees: a review. Foot and Ankle Surgery, Volume 14(3), pp. 125-129.

[15] Tryggvason, L, et al. 2020, Use of Dynamic FEA for Design Modification and Energy Analysis of a Variable Stiffness Prosthetic Foot. Applied sciences 10(650), Vol. 10, pp. 1-12.

[16] Jalil, M. Abdul. Analisis Sifat Mekanik pada Komposit Berpenguat Serat Karbon Metode Out-of-Autoclave dengan Proses MRCC dan EMRCC untuk Aplikasi Kaki Pelari Prostetik. Semarang, Jawa Tengah, Indonesia : Universitas Diponegoro, Mei 2021.

[17]. Ashutosh Kharb, et al., 2011, A Review of Gait Cycle and its Parameters. IJCEM International Journal of Computational Engineering \& Management Volume 3.

[18] M. Hannan Ahmed, et al., 2015, Actuator Design for Robotic Powered anAnkle-Foot prosthesis. IEEE, Bioelectronics and Bioinformatics (ISBB) International Symposium.

(C) 2021. This article is an open access article distributed under the terms and conditions of the Creative Commons Attribution (CC BY) license (http://creativecommons.org/licenses/by/4.0/) 